\title{
Aspects of determining biomass-based levoglucosenone by UHPLC-UV in aqueous samples
}

\author{
Kristine Meile $e^{1,2^{*}}$, \\ Daniela Godina ${ }^{1,2}$, \\ Aivars Zhurinsh', \\ Ralfs Pomilovskis ${ }^{1}$ \\ ${ }^{1}$ Latvian State Institute \\ of Wood Chemistry, \\ 27 Dzerbenes Street, \\ 1006 Riga, Latvia \\ ${ }^{2}$ University of Latvia, \\ Faculty of Chemistry, \\ 1 Jelgavas Street, \\ 1004 Riga, Latvia
}

The depletion of fossil resources and concerns about the environment encourage the search for renewable biomass-based chemicals with broad applications. Levoglucosenone (LGO) is a carbohydrate derivative obtained by the pyrolysis of cellulose containing raw materials. Because of its two chiral centres LGO is particularly appealing to the organic synthesis industry, therefore improved ways of producing LGO are continuously investigated. This study deals with the quality control of the LGO containing pyrolysis products by modern UHPLC-UV methods. Acceptable chromatographic separation of LGO could be achieved in most samples of pyrolysis products obtained from birch (Betula pendula) wood. However, a significant degradation of LGO was observed in aqueous solutions, which needs to be taken into consideration both when performing analysis, as well as during the storage of the pyrolysis products which are generally recovered from the pyrolysis reactor as a water condensate. The degradation rate of LGO in a water/acetonitrile solution, which corresponds with the mobile phase of the UHPLC method, at $5^{\circ} \mathrm{C}$ was $1.8 \%$ a day. Even faster degradation occurred in samples without the addition of acetonitrile.

Keywords: pyrolysis, levoglucosenone, stability, chromatography

\section{INTRODUCTION}

The importance of replacing fossil resources by biomass-based chemicals in the global economy arises from concerns about the environment, as well as the predicted depletion of oil production [1]. Wood is a common, readily available source of biomass, which can be conversed not only into energy and fuels, but also chemicals, such as (1S, 5R)-6,8-dioxabicyclo[3.2.1] oct-2-en4 -one or levoglucosenone (LGO).

\footnotetext{
*Corresponding author. Email: kristine.meile@inbox.lv
}

Levoglucosenone is 1,6-anhydrosugar with a unique bicycle structure. The 1,6-anhydro bridge secures a stable pyranose ${ }^{1} \mathrm{C}_{4}$ conformation, which in combination with the two chiral centres $\left(\mathrm{C}_{1}\right.$ and $\mathrm{C}_{5}$ ) makes LGO a particularly appealing substrate for organic synthesis [2]. Levoglucosenone derived solvents have a potential to replace currently used hazardous solvents, such as dichloromethane and nitrobenzene [3]. The most recognized example of LGO application is the production of Cyrene $^{\mathrm{TM}}$ (dihydrolevoglucosenone), a promising dipolar aprotic solvent [4], accomplished by the Circa Group in Australia [5]. Furthermore, 
LGO can be used to synthesise 1,6-hexanediol which is an important feedstock in the polymer industry [6], and even pharmaceuticals [7], 8].

LGO can be produced by an organic synthesis pathway [9], but a more practical approach is to obtain LGO from wood or other lignocellulosic material [10]. LGO is formed by the depolymerisation and dehydration of cellulose in the process of selective catalytic pyrolysis at comparatively low temperatures. The choice of a catalyst is reported to have the main influence on the yield of LGO from the pyrolysis process [11]. LGO is recovered from the pyrolysis reactor in the liquid condensable fraction or pyrolysis oil which also contains many byproducts - other anhydrosugars, furans, phenols, and organic acids [12].

Most commonly, pyrolysis products containing LGO are analysed by gas chromatography (GC). A significant advantage of GC coupled with mass spectrometry is the possibility to identify compounds by using the NIST MS library [13, 14, however, the quantitative analysis results are often only the relative peak areas instead of absolute concentration values. For the quantitative analysis the use of 1,2, 4, 5-tetramethylbenzene has been reported as an internal standard to improve the quantitative results of GC with a flame ionisation detector [14, 15. In the presented study ultra-high performance liquid chromatography (UHPLC), a method which is rapidly becoming a 'must-have' in analytical laboratories, was used to analyse wood pyrolysis products. The advantages of UHPLC compared to HPLC are the increased speed, reduced cost, improved resolution and sensitivity [16].

It can be concluded that liquid chromatography is not the first choice of analysis for LGO containing pyrolysis products, because in reversed phase chromatography LGO partially or completely overlaps with 5-hydroxymethylfurfural (HMF) [6, 17]. In most cases, when LGO is analysed by liquid chromatography, the detection is performed by UV or photodiode array detectors set at 210 [18] or $220 \mathrm{~nm}$ [8, 17]. In the case of LGO and HMF co-elution the $370 \mathrm{~nm}$ detection for LGO has been chosen, while HMF was measured at $290 \mathrm{~nm}$, but this approach requires careful considerations about the contribution of each of the overlapping compounds to the signal intensity [19]. A refractive index detector is only mentioned for the quantification of the hydrated form of LGO [19].
In our practical work we have observed that the degradation of the LGO molecule in solutions - either standard solutions for calibration or aqueous samples - can be a significant problem in the analytical UHPLC procedures, therefore the aim of this study is to investigate the stability of LGO in aqueous solutions and its effect on the results of the UHPLC analysis of pyrolysis products containing LGO.

\section{EXPERIMENTAL}

\section{Materials and chemicals}

Levulinic acid (99\%), 5-hydroxymethylfurfural HMF ( $\geq 99 \%$ ), levoglucosenone LGO (99\%) and furfural (99\%) were purchased from Sigma-Aldrich and used without further purification. For the UHPLC analysis LC-MS LiChrosolv acetonitrile, Millipore Type 1 water and LC-MS LiChrosolv acetone were used. All solutions were filtered through Kinesis nylon syringe filters $(0.22 \mu \mathrm{m})$ before the analysis.

\section{Samples}

Pyrolysis liquid samples were prepared, using lignocellulose obtained from hydrolysed birch (Betula pendula) chips. Ground birch wood (0.40$0.63 \mathrm{~mm}$ ) was impregnated with an aqueous solution of phosphoric acid (5 wt $\%$ on a dry basis of the raw material), then the impregnated material was dried at $103^{\circ} \mathrm{C}$ and fed into the auger reactor. The pyrolysis temperature was $340^{\circ} \mathrm{C}$, each experiment used $80 \mathrm{~g}$ of raw material. The feed rate was $12 \mathrm{~g} / \mathrm{min}$, the average residence time in the reactor was $1.3 \mathrm{~min}$, and nitrogen was the carrier gas with the flow rate $0.3 \mathrm{~L} / \mathrm{min}$. The product vapours were passed through a Liebig condenser and the liquid products were collected in a receiving flask. Tentative experiments of extraction were done with chloroform, followed by solvent removal using rotary evaporation at reduced pressure.

\section{UHPLC analysis}

Quantitative measurements of LGO were done using a Waters Acquity H-Class UPLC system (USA). Four Waters UPLC columns were tested for the separation of LGO and other pyrolysis products: CORTECS HILIC $(1.6 \mu \mathrm{m}, 2.1 \times 150 \mathrm{~mm})$, BEH Amide $(1.7 \mu \mathrm{m}, 2.1 \times 100 \mathrm{~mm})$, HSS C18 $(1.7 \mu \mathrm{m}, 2.1 \times 100 \mathrm{~mm})$ and CSH Phenyl-Hexyl 
$(1.7 \mu \mathrm{m}, 2.1 \times 100 \mathrm{~mm})$. The column temperature in all cases was $30^{\circ} \mathrm{C}$, but the composition of the mobile phase depended on the column type. For the HILIC column the mobile phase was the $10 \mathrm{mM}$ ammonium formate buffer in water/ acetonitrile (10:90) with the flow rate $0.4 \mathrm{~mL} / \mathrm{min}$, for the Amide column it was $0.05 \% \mathrm{NH}_{3}$ in water/ acetonitrile (30:70) with the flow rate $0.15 \mathrm{~mL} /$ min, for the C18 and Phenyl-Hexyl columns it was $0.1 \%$ formic acid in water/acetonitrile (90:10) for $2.5 \mathrm{~min}$ followed by gradient to water/acetonitrile (10:90) and an equilibration step back to the initial composition for $10 \mathrm{~min}$ with the flow rate $0.4 \mathrm{~mL} / \mathrm{min}$. The injection volume was $2 \mu \mathrm{L}$. The analysis was performed in triplicate. UV absorption was measured at 220, 275 and $350 \mathrm{~nm}$. To evaluate the separation of the pyrolysis products the retention factor $k^{\prime}$ and $\alpha$ (selectivity) were calculated by Eqs. (1) and (2), based on the retention times $t_{R}$ :

$$
\begin{aligned}
& k^{\prime}=\frac{t_{R}-t_{0}}{t_{0}}, \\
& \alpha=\frac{k_{2}{ }^{\prime}}{k_{1}{ }^{\prime}} .
\end{aligned}
$$

Tests were done to evaluate the repeatability and trueness of the optimal UHPLC method with the Phenyl-Hexyl column. Repeatability was characterised by the relative standard deviation of six replicates. Trueness was characterised by the recovery of standard LGO in the samples of pyrolysis products spiked with $0.2,0.4$ and $0.7 \mathrm{mg} / \mathrm{mL}$ of LGO. The limit of detection (LOD) was calculated based on the standard deviation SD of five measurements by Eq. (3):

$$
\mathrm{LOD}=\frac{3 \cdot \mathrm{SD}_{5}}{\text { slope }}
$$

Replacing acetonitrile with acetone in the mobile phase was explored to reduce the decomposition of LGO in the solutions, and also because acetone is considered a much 'greener' solvent [20].

\section{Stability of LGO}

$2.00 \mathrm{mg} / \mathrm{mL}$ LGO was dissolved in water, water/ acetonitrile (50:50), acetonitrile, water/acetone (50:50) and acetone, and filtered into several UHPLC vials, which were stored at room temperature $\left(21 \pm 1^{\circ} \mathrm{C}\right)$ or refrigerated $\left(5 \pm 1^{\circ} \mathrm{C}\right)$ for up to three months. After time intervals of several days the solution was analysed by UHPLC-UV using the Phenyl-Hexyl column to observe a decrease of the LGO peak areas. The pyrolysis product samples containing LGO were diluted with water/acetonitrile to the concentration $10.5 \mathrm{mg} / \mathrm{mL}$, stored at both temperatures and analysed as described previously. Kinetic curves were constructed to depict the decrease of the relative concentration of LGO by time $(\mathrm{LGO} \%)=f$ (time). The overall LGO (\%) degradation rate $r$ in time $t$ was calculated by Eq. (4):

$$
r=-\frac{\mathrm{LGO}_{0}-\mathrm{LGO}}{t_{0}-t} .
$$

\section{RESULTS AND DISCUSSION}

\section{Optimisation of the UHPLC-UV method}

In order to analyse LGO by UHPLC, four chromatographic columns were evaluated by determining the retention factor $k^{\prime}$ and selectivity a of LGO, and several typical pyrolysis by-products - furfural, HMF and levulinic acid. It was found that the best separation of LGO and the other compounds could be achieved by the Phenyl-Hexyl column. In this case the retention factors $k^{\prime}$ for levulinic acid, HMF, LGO and furfural were $0.69,0.89,1.3$ and 1.5 , respectively. The chromatographic peaks of LGO and HMF have been reported to completely overlap [6], while in our study these compounds can be sufficiently separated. The best selectivity was between LGO and levulinic acid $(\alpha=1.9)$, but the selectivity between LGO and HMF or furfural was 1.5 and 1.1, respectively. The relative standard deviation RSD of the retention times between the three parallel injections was $<1.5 \%$ in all cases.

It was found that two wavelength values could be used for the detection of LGO - 220 or $350 \mathrm{~nm}$. UV detection of LGO at $220 \mathrm{~nm}$ is widely described in literature, because of the better sensitivity. Figure 1 shows a good example of the absorption values at different wavelengths for the same injection - the signal intensity of LGO at $220 \mathrm{~nm}$ was about 70 times bigger than at $350 \mathrm{~nm}$. However, detection at $350 \mathrm{~nm}$ is more specific, because furfural has less absorption at this wavelength compared to $220 \mathrm{~nm}$. In Fig. 1 there is a significant difference between the intensity of the furfural peak at 220 and $350 \mathrm{~nm}$, therefore in samples 


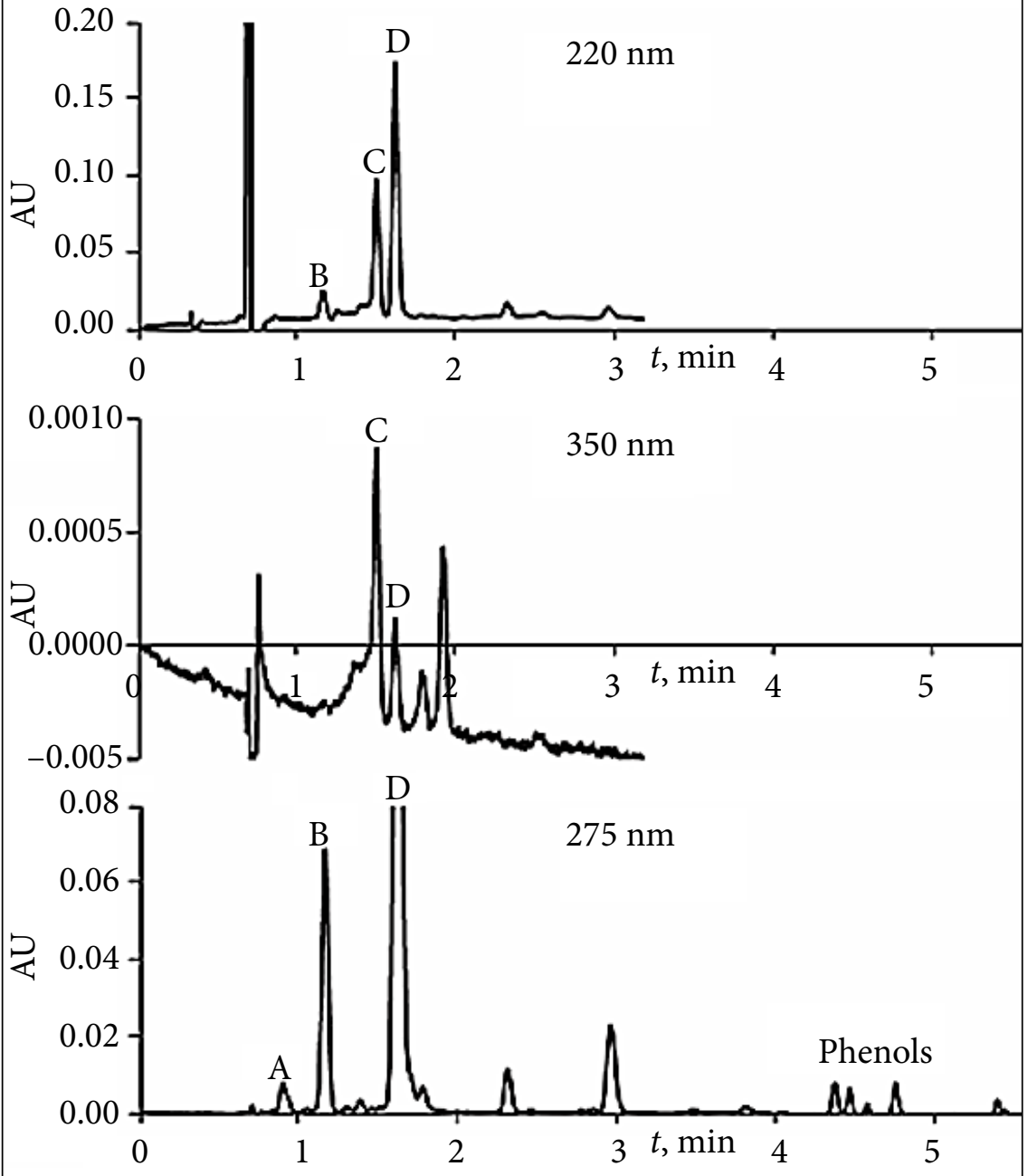

Fig. 1. UHPLC-UV chromatograms of pyrolysis products at 220,275 and $350 \mathrm{~nm}$ with the HSS C18 column: A, levulinic acid $(t R=0.90 \mathrm{~min})$; $B, H M F(t R=1.15 \mathrm{~min}) ; C, L G O$ $(t R=1.50 \mathrm{~min}) ; \quad D$, furfural $(t R=1.61 \mathrm{~min})$ with a notable concentration of furfural it might be advisable to use detection at $350 \mathrm{~nm}$ to avoid peak overlapping. On the other hand, if it is necessary to determine the amount of HMF and furfural, detection at $275 \mathrm{~nm}$ should be chosen. On the whole, in various pyrolysis products the main components were LGO $(0.05-0.1 \mathrm{mg} / \mathrm{mL})$ and furfural $(0.03-0.7 \mathrm{mg} / \mathrm{mL})$, followed by HMF and minor concentrations of different unknown compounds, including phenols which were eluted after $4 \mathrm{~min}$.

For the quantitative determination of LGO in pyrolysis products the UHPLC-UV method using the Phenyl-Hexyl column and detection at $220 \mathrm{~nm}$ was partially validated. The trueness of the method was determined by the recovery of spiked samples, which was $98 \pm 4 \%$ when spiked with $0.2 \mathrm{mg} / \mathrm{mL}$ LGO, $99 \pm 3 \%$ (for $0.4 \mathrm{mg} / \mathrm{mL}$

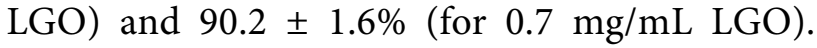
The repeatability of the method was characterised by the RSD of six replicate injections which was $<5 \%$. The limit of detection LOD was $0.04 \mathrm{mg} / \mathrm{mL}$.
A good linearity with $\mathrm{R}^{2}>0.999$ was observed in the concentration range from 0.04 to $1 \mathrm{mg} / \mathrm{mL}$.

Changing the organic constituent of the mobile phase to acetone did not improve the analysis method in any way. Although the repeatability was not decreased by the exchange $(R S D<2 \%)$, there were several drawbacks. First of all, the UV cutoff of acetone is higher than that of acetonitrile, thus tampering with the detection of the analytes. Secondly, the selectivity a of LGO and the pyrolysis by-products decreased with the introduction of acetone to 1.7 for levulinic acid and only 1.0 for furfural (completely overlapping). The selectivity of LGO/HMF was still 1.5, but because of peak broadening HMF overlapped with levulinic acid.

\section{Stability of LGO in various solutions}

A significant decrease of the LGO concentration in the pyrolysis products over time was observed, therefore the stability of aqueous solutions was investigated. Figure 2 depicts the decrease of the concentration of a standard LGO in different 


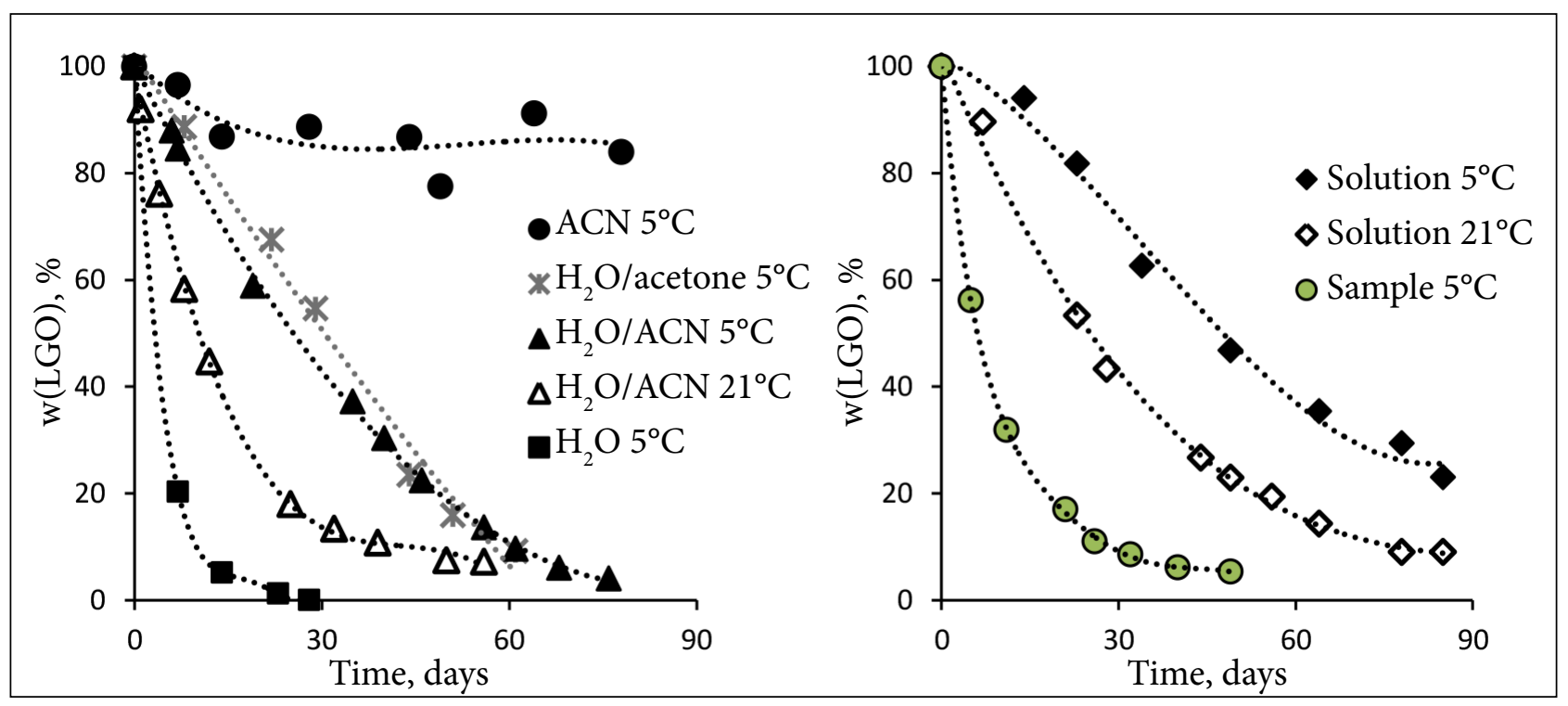

Fig. 2. The decrease of the concentration of LGO during storage: to the left - in different standard solutions; to the right - in a pyrolysis liquid sample without dilution or diluted in water/acetonitrile solutions

water/acetonitrile solutions, as well as in the samples of pyrolysis products. Acetonitrile was chosen as the second solvent, because the optimal UHPLC analysis was performed with a water/acetonitrile gradient system. First of all, it was found that LGO was less stable in water than in acetonitrile. In a refrigerated aqueous solution the standard LGO was completely degraded within 30 days. If LGO was dissolved in water/acetonitrile (50:50) and stored at $5^{\circ} \mathrm{C}$, its concentration decreased by $95 \%$ in less than 80 days. In $100 \%$ acetonitrile LGO was significantly more stable - during 90 days of storage the concentration of LGO remained $>80 \%$ of the starting concentration. The degradation of LGO in water in the first two weeks was practically linear with the reaction rate $4.7 \%$ a day, but in acetonitrile only $0.2 \%$ a day. LGO isomerisation to HMF and further degradation in acidic water solutions have been described in literature [19].

The influence of temperature on the stability of LGO was also observed. A standard solution of LGO in water/acetonitrile stored at room temperature was rapidly degraded by $80 \%$ in 25 days and further degraded to $5 \%$ in 60 days. The same solution stored at $5^{\circ} \mathrm{C}$ degraded more gradually, reaching the LGO concentration $<5 \%$ in 80 days. The overall degradation rate of LGO in a water/ acetonitrile solution at $5^{\circ} \mathrm{C}$ was $1.3 \%$ a day, but at room temperature the process was faster $-1.7 \%$ a day. On the whole, the degradation was not a linear process, and the reaction rate was significantly higher in the first month -1.8 and $2.7 \%$ a day at 5 and $21^{\circ} \mathrm{C}$, respectively. It means that samples diluted for the UHPLC analysis in the water/acetonitrile solvent should be analysed as fast as possible to avoid a decreased result.

When using acetone instead of acetonitrile, the stability of LGO improved in the absence of water - the concentration of the standard LGO in the refrigerated acetone solution remained the same for a month and even longer, but in the water/acetone solution the LGO degradation rate was similar to that in the water/acetonitrile solution $-1.5 \%$ a day. Although acetone and acetonitrile are both polar aprotic solvents, the more pronounced stabilising effect of acetone can be attributed to its lower dipole moment and dielectric constant. For a comparison, the acceptable stability of LGO in tetrahydrofuran (even lower dipole moment and dielectric constant) has been recently described in literature [21]. Taking into consideration the dissatisfactory UHPLC separation with acetone in the mobile phase, acetonitrile seems to be a better choice for sample preparation and analysis. However, a stock solution of LGO in acetone could be used to avoid degradation and wasting of the rather expensive reference material.

Similar trends were observed in the case of real pyrolysis products - LGO in refrigerated water/ acetonitrile solutions of the pyrolysis products degraded more slowly than at room temperature. Besides, the initial samples without the addition 
of any solvents also showed a strong tendency to degrade even at $5^{\circ} \mathrm{C}$. The LGO degradation rate during the first ten days of storage was a rapid linear process with the reaction rate $6.2 \%$ a day, slowing down to $0.7 \%$ a day afterwards. Therefore the aqueous pyrolysis condensates are not suitable for long-term storage and need to be further processed in order to recover the maximum LGO yield. In literature the most widely described method of concentrating LGO is liquid-liquid extraction followed by distillation [22]. During the extraction process LGO is removed from the water phase, thus decreasing the involuntary degradation of LGO. Alternatively, LGO can be separated from the aqueous phase by preparative liquid chromatography [23]. Our preliminary experiments have shown that LGO containing extracts obtained from the aqueous pyrolysis condensates by chloroform extraction followed by distillation are significantly more stable in terms of LGO degradation in time. However, further investigations are needed to select an optimal LGO separation technique, as the concentration of LGO in the mentioned extracts still decreased by $20-30 \%$ in 60 days.

\section{CONCLUSIONS}

An optimal analysis of LGO containing pyrolysis product condensates could be achieved by a UHPLC-UV method using a Phenyl-Hexyl derived column with a water/acetonitrile gradient and UV detection at 220 or $350 \mathrm{~nm}$ wavelength for LGO and $275 \mathrm{~nm}$ for HMF and furfural. However, degradation of LGO (up to $6 \%$ a day) can raise concerns about the accuracy of results obtained by reversed phase liquid chromatography using aqueous mobile phases. Addition of acetonitrile increased the stability of LGO in standard solutions, as well as the samples of pyrolysis liquids. Refrigeration of the samples decreased the degradation rate of LGO in all cases. On the whole, storage of the aqueous pyrolysis product condensates is not advisable, because of a significant loss of LGO, instead the condensates need to be distilled or otherwise fractionated to maintain an acceptable yield of LGO.

\section{ACKNOWLEDGEMENTS}

This research was supported by ERDF Project No. 1.1.1.1/16/A/010 'Developing an Innovative
Technology for Producing Levoglucosenone from Lignocellulose’.

Received 31 October 2018 Accepted 13 February 2019

\section{References}

1. E. de Jong, A. Higson, P. Walsch, M. Wellisch, Biobased Chemicals. Value Added Products from Biorefineries, IEA Bioenergy - Task 42 Biorefinery (2012).

2. A. M. Sarotti, Carbohyd. Res., 390, 76 (2014).

3. A. Alves Costa Pacheco, J. Sherwood, A. Zhenova, et al., ChemSusChem, 9(24), 3503 (2016).

4. J. Sherwood, M. De Bruyn, A. Constantinou, et al., Chem. Comm., 50(68), 9650 (2014).

5. Products. Levoglucosenone [http://www.circagroup. com.au/levoglucosenone/].

6. F. Cao, T. J. Schwartz, D. J. McClelland, S. H. Krishna, J. A. Dumesic, G. W. Huber, Energy Environ. Sci., 8, 1808 (2015).

7. M. Ostermeier, R. Schobert, J. Org., 79(9), 4038 (2014).

8. A. R. S. Teixeira, A. L. Flourat, A. A. M. Peru, F. Brunissen, F. Allais, Front. Chem., 4, 16 (2016).

9. M. Shibagaki, K. Takahashi, H. Kuno, I. Honda, H. Matsushita, Chem. Lett., 19(2), 307 (1990).

10. Z. Zhang, Q. Lu, X. N. Ye, T. P. Wang, X. H. Wang, C. Q. Dong, Bioenerg. Res., 8, 1263 (2015).

11. Q. Lu, X. Ye, Z. Zhang, C. Dong, Y. Zhang, Bioresource Technol., 171, 10 (2014).

12. W. Wang, Y. Shi, Y. Cui, X. Li, J. Anal. Appl. Pyrol., 131, 93 (2018).

13. H. Zhang, X. Meng, C. Liu, Y. Wang, R. Xiao, Fuel Process. Technol., 167, 484 (2017).

14. X. Sui, Z. Wang, B. Liao, Y. Zhang, Q. Guo, Bioresource Technol., 103(1), 466 (2012).

15. X. Wei, Z. Wang, Y. Wu, Z. Yu, J. Jin, K. Wu, J. Anal. Appl. Pyrol., 107, 150 (2014).

16. L. Novakova, L. Matysova, P. Solich, Talanta, 68(3), 908 (2006).

17. H. Kawamoto, W. Hatanaka, S. Saka, J. Anal. Appl. Pyrol., 70(2), 303 (2003).

18. S. Kudo, Z. Zhou, K. Yamasaki, K. Noringa, J. Hayashi, Catalysts, 3, 757 (2013).

19. S. H. Krishna, T. W. Walker, J. A. Dumesic, G. W. Huber, Chem. Sus. Chem., 10(1), 129 (2017).

20. C. S. Funari, R. L. Carneiro, M. M. Khandagale, A. J. Cavalheiro, E. F. Hilder, J. Sep. Sci., 38(9), 1458 (2015).

21. J. He, M. Liu, K. Huang, et al., Green Chem., 19(15), 3642 (2017).

22. J. A. Marshall, Ph. D. Thesis, Iowa State University (2008).

23. A. M. Sarotti, R. A. Spanevello, A. G. Suárez, Green Chem., 9(10), 1137 (2007). 
Kristine Meile, Daniela Godina, Aivars Zhurinsh, Ralfs Pomilovskis

LEVOGLIUKOZENONO, GAUTO IŠ BIOMASĖS, NUSTATYMO VANDENINIUOSE PAVYZDŽIUOSE UHPLC-UV METODU ASPEKTAI

Santrauka

Levogliukozenonas (LGO) yra angliavandenis, gaunamas pirolizès būdu iš celiuliozès turinčių žaliavų. Dèl jo struktūroje esančių dviejų chiralinių centrų LGO yra perspektyvus organineje sintezèje.

Pasitelkus modernų UHPLC-UV metodą, buvo atliekama LGO analizè beržo medienos pirolizès produktuose. Nustatytos tinkamos LGO chromatografinio perskyrimo sąlygos ir ištirtas jo irimas vandeniniuose tirpaluose. 